\title{
Decision support for vessel traffic service (VTS): user needs for dynamic risk management in the VTS
}

\author{
Gesa Praetorius* and Margareta Lützhöft \\ Department of Shipping and Marine Technology, Chalmers University of Technology, SE-412 96 Gothenburg, \\ Sweden.
}

\begin{abstract}
Vessel Traffic Service (VTS) is a shore-side service implemented by a "Competent Authority to improve the safety and efficiency of vessel traffic and to protect the environment". It is a service that operates through VTS centers, from which VTS operators monitor traffic, assist in navigational matters and provide information to all ships in a designated area. As VTS is provided by operators located on shore, they usually make use of several decision support systems to be able to monitor the traffic and to provide information to the vessels. Although several new tools and approaches have been introduced in the VTS domain, there is still room for improvements. This paper summarizes the results from three studies conducted within the EfficienSea project to approach user needs for dynamic risk management in the VTS domain. Data was collected by conducting study visits and observations at VTS centers, a focus group interview as well as several semi-structured interviews. The paper summarizes the results and presents technical and organizational user needs for dynamic risk management within the VTS domain.
\end{abstract}

Keywords: Vessel Traffic Service (VTS), user needs, decision support, maritime safety

\section{Introduction}

Vessel Traffic Service (VTS) is a shore-side service implemented by a "Competent Authority to improve the safety and efficiency of vessel traffic and to protect the environment" [1]. It is a service that operates through VTS centers, from which operators monitor the traffic, assist in navigational matters and provide information to all vessels in a designated area. In many sensitive sea areas and areas with a high traffic density VTS centers have been established through the past decades [1].

As VTS is provided by operators located on shore, they usually make use of various decision support systems to be able to deliver a safe, efficient and effective service to the maritime community. Although new tools and approaches, such as e-Navigation, supporting the decision making process in VTS centers have been introduced as part of integrated support systems in the past decade [2, 3], there is still room for improvements. There are, for example, difficulties to reach common technical or systemspecific user needs valid for all VTS operators regarding dynamic risk management. The demands of the experts differ depending on the level of service offered by the center, and on the area monitored as well as the traffic density in it.

This paper summarizes the results from three studies conducted within the VTS domain to approach common user needs for dynamic risk management. These studies were conducted within the EfficienSea Project. Data was collected by three study visits at VTS centers (Ymuiden, Hook of Holland, Sound VTS Malmo), three observations (one in a VTS center, two on board merchant vessels), one focus group, and 20 interviews ( 8 VTS operators, 9 officers, 3 representatives of the Swedish maritime domain).

We approach the VTS domain from a sociotechnical systemic perspective, including not only the technology and the human on the shore-side, but also

*Corresponding author. E-mail: gesa.praetorius@chalmers.se 
taking the navigators, or customers, into concern that make use of the services offered by a VTS center in a specific area. The data obtained were analyzed using concepts derived from Naturalistic Decision Making (NDM, e.g.[4-6]) and from the theoretical framework of High Reliability Organizations (HRO, e.g. [7, 8]).

\subsection{Vessel Traffic Service (VTS) and the maritime domain}

The VTS is a shore-side service to increase the safety and efficiency of vessel traffic in a determined area, a VTS area. The VTS is regulated internationally but implemented locally by a Competent Authority in a country (e.g. the Swedish Maritime Administration in Sweden) to assist, monitor and organize maritime traffic. There are three different types of shore-based services connected to VTS; information service (INS), navigational assistance (NAS) and traffic organization (TOS) [1].

Information service (INS) is a service offering all essential information to the vessels within the VTS area. Essential information may either contain facts on the VTS area, e.g. intentions, boundaries, procedures, radio channels, reporting points, or information concerning variables influencing the navigation and maneuverability of a ship, e.g. upcoming vessel meetings, status of aids to navigation, traffic congestions, meteorological information etc. [1].

Navigational assistance (NAS) is a service with the aim to support the navigational decision making on board followed by monitoring its effects. NAS consists of two parts, navigational information and navigational advice. Navigational information may contain the course and speed made by a vessel, warnings to specific vessels and positions of other traffic as well as positions relative to fairway axes and waypoints. Navigational advice is an active participation in the on board navigational decision making of a ship. It is up to the Competent Authority to decide whether and under which circumstances the VTS can and may assist the navigational decision making of vessels in the VTS area [1]. However, IMO states that in case of navigational assistance, the instructions given to vessels should be result-oriented; leaving all details of execution to the master or pilot on board the vessel [9].

Traffic Organization Service (TOS) is a service with the objective to keep the traffic movements safe, fluent and efficient within the VTS area. Furthermore, TOS is concerned with the proactive planning of traffic movements, especially in the case of congestions or other aspects which might impact on the traffic in the area. Monitoring the traffic and establishing compliance to the prevailing rules in the area are a part of this service.

As mentioned earlier, although regulated on an international level, the VTS is in general implemented locally. This means that whatever services are offered is dependent on what the Competent Authority judges to be adequate. In Sweden, for example, the VTS is solely an information service. TOS is only offered in the Gothenburg area and it is restricted to giving berth clearance. In other countries, such as the Netherlands, NAS is quite common when weather conditions do not allow a pilot to board. NAS is then provided as a form of shore-based pilotage. In such cases the shore-based pilot is located at a station in the VTS center and gives result-oriented advice to vessels in the approach to the harbor entrance [10].

\subsection{Usability and user needs}

Usability is the "extent to which a product can be used by a specified user to achieve specified goals with effectiveness, efficiency and satisfaction in a specific context of use. "[11]

ISO 9241-11 defines usability as something that enables a user to achieve goals in a specific context. The focus is on assessing the whole work system in naturalistic settings with the help of three concepts: effectiveness, efficiency and user satisfaction.

Effectiveness measures the accuracy and completeness with which a user achieves specific goals. Accuracy and completeness can for example be measured by quality and quantity of the output. Efficiency focuses on the amount of resources used in relation to the effectiveness with which a user achieves his/her goals. Resources in this case might be time, physical and mental energy spent on a task and/or the material and financial cost of it. User satisfaction is defined as "freedom from discomfort". It is the user's response to the interaction with a product and it can be assessed by both subjective and objective measures, e.g. observations, questionnaires, attitudes, opinions.

Another important aspect in the above definition of usability is the focus on naturalistic settings or what is called the "context of use". It consists of users, tasks, equipment and the physical and social environment the users act in. This emphasizes that it is not the product as such, but the context of use itself, which influences a product's usability. 
In order to obtain user needs, the emphasis in the studies presented here primarily is the context of use and the user satisfaction of the VTS operators. The studies have approached the VTS as a whole system including both technical, such as electronic information systems, and non-technical decision support, organizational settings, and the overall legal framework which guides the operators in their work.

\section{Methodology}

This paper presents the results of three studies, one focused on the decision settings in the VTS, one on the VTS as HRO and one study focusing on the understanding of maritime safety from a ship's bridge perspective.

All studies made use of ethnographically inspired methods - observations, interviews and focus groups - and they were focused on the concept of maritime safety from the operators' perspective. The aim was to understand safety at the sharp end in the maritime domain in order to develop concepts which describe the decision making within the high hazardous domain of Vessel Traffic Service.

\subsection{The three studies}

The first study approached the VTS as a domain for naturalistic decision making $[6,12]$. It focused on the settings in which VTS operators make decisions and on how safety relates to the decision making process of the operators. Three study visits at VTS centers (Malmo, Ymuiden, Hook of Holland) coupled with contextual inquiries were conducted. All in all, 3 VTS operators and 5 shore-based pilots were interviewed during the study visits. Furthermore, a focus group on decision support user needs was conducted [13].

The second study was a complementary study to study 1. VTS was approached on an organizational level by identifying various characteristics of a High reliability organization. All in all, 8 VTS operators and 3 representatives for legal organizations within the Swedish maritime domain (Swedish Maritime Administration, Swedish Transport Agency, Swedish Shipowners' Association) were interviewed on the role of the VTS in relation to safety within the maritime domain [14].

The third study was concentrated on the concept of maritime safety from a crew perspective. 32 interviews with crewmembers of merchant vessels and two five-day long observations were conducted. Nine of the informants were serving as officers or masters at these vessels [15]. These nine interviews were considered relevant for this article.

\subsection{Data collection}

The following paragraphs summarize the data collection for the user needs analysis.

\subsubsection{Study visits}

Three VTS centers (Sound VTS Malmo, Traffic Centre Hook of Holland, and Harbor Operation Centre Ymuiden) were visited. During the visits contextual inquiries of VTS operators were conducted.

In addition to interviewing experts in their daily work environment, the study visits also aimed at increasing the understanding of what kind of technical equipment is used today to provide vessel traffic service in different areas and what needs there are today that have to be addressed by future developments. During each visit, the operators' working environment was observed and the operators were asked questions in relation to the work they conducted.

\subsubsection{Interviews}

Data from 20 interviews (8 VTS operators, 9 bridge officers and 3 representatives for central organizations within the Swedish maritime domain) have been collected in the three studies. All interviews were semi-structured and followed an interview guide including questions on the function, purpose and expectations towards the VTS as an organization providing a service to the maritime domain.

\subsubsection{Focus group}

As part of study one, a focus group interview with 8 VTS operators was conducted at Aboa Mare, the Maritime Institute of Åbo (Turku) Swedish Maritime School. This group interview focused on the VTS operators' use of decision support systems.

During the session following three questions were discussed:

1. Rank the following decision support tools according to their importance for your daily work! Which one is most important, which one least?

- VHF, CCTV, Telephone/mobile phone, GPS/DGPS, AIS, RADAR, ECDIS, Hydro meteorological information, Databases, e.g. PortNet (please specify which ones), Internet.

2. What characterizes a conflicting situation? 


\author{
3. How would you define "good VTS- \\ service"?
}

\subsubsection{Observations}

To complement the interview data, two observations were conducted, one at a VTS center and one on board of two merchant vessels.

The observation at the VTS center was performed in two days during daytime. The purpose was to follow the normal working procedures and routines of a VTS operator at work and the interaction with various actors, e.g. different vessels, port operators and pilots. The observation was open and passive due to the safety-critical work environment. The operators were followed by one observer taking notes and photos during the work. Furthermore, contextual inquiry was used to obtain more information on how and why the operators were taking certain actions.

As part of study three two five-day long observations on board of merchant vessels were conducted. The observations were open and passive due to the safety-critical environment on board. Most of the time was spent on the bridge observing the working routines and interactions of the bridge team with other actors, e.g. other crewmembers, pilots and VTS operators. Further, contextual inquiries were conducted during the observation to get a better understanding for how the subjects reasoned about the tasks performed during the normal operation of the vessel.

\subsection{Data analysis}

All data collected were analyzed with the help of the concepts efficiency, effectiveness and user satisfaction. The interview data were transcribed verbatim and field notes collected during observations and study visits were sorted according to the concepts. The focus of the analysis was the VTS as a whole system to be able to understand the operators' needs concerning future technology, but also concerned the organizational and legal settings of their work.

\section{RESULTS}

Results obtained in the studies reflect different aspects of the VTS as a system. Study one focused on the decision making settings, study two on the organizational settings and study three emphasized the bridge teams' perspective as customers to the VTS.

\subsection{Study 1}

The results of study one show that VTS operators deal with a variety of situations during their daily work, which sets up various levels of conflict that need to be solved by the operators while they are providing a service. Multiple players with conflicting goals have expectations which the operator has to solve. In general, problems in this domain are hard to foresee and they occur not seldom in an ill-structured way, meaning that the operator needs to look actively for how a situation could possibly develop into an anomaly [13]. This is in agreement with findings in high hazardous domains, such as fire-fighting, where experts make their decisions under extreme time pressure with conflicting and often ill-defined goals. Decisions in such settings are heavily based on expert knowledge and prior experience [5].

The VTS operators in the study highlighted that their decision making depends heavily on the uncertain and dynamic environment. This makes decisions on whether to interact with the traffic highly contextdependent. Factors such as traffic density, information presented in the technical system at hand, response of the bridge team towards calls, or geographical particulars of the area can all have an impact on the operator's decision.

It was further concluded that the choice of action of a VTS operator is highly dependent on his/her assessment of a specific situation. Working experience on board of vessels as well as on shore and expertise were found to be the key ingredients for decision making in the VTS domain [13].

\subsection{Study 2}

Study 2 focused the VTS as a High Reliability Organization (HRO) and on the concept of maritime safety in the VTS domain [14].

The results of the study show that VTS operators define safety as a context-dependent condition in which their own actions have an impact on how situations develop. The educational background, expert knowledge and working experience in combination with the information displayed in the decision support system come together in the choice of action of the VTS operator. Safety in the VTS domain then becomes a dynamic condition which is constructed by the interaction of the VTS operator with other actors, such as pilots, operational staff, and bridge teams [14]. 
The results of the study further show that one of the central concepts, maritime safety, in the maritime domain is rather poorly defined and that this needs to be overcome by constructing common values, norms and identities for the actors within this domain. There is the urgent need for a mutual understanding between the operational staff on the sharp end (VTS operators) and the management (legal organizations in the maritime domain) on the blunt end. Safety should be acknowledged as a dynamic condition and focus should be put to the positive impact that the VTS as an organization has on the overall maritime safety. Consequently, the role of the VTS as service to the maritime community needs to be highlighted, so that this specific organization's impact is finally recognized as crucial for the overall safety in the domain [14].

\subsection{Study 3}

The results of study three indicate that the navigators have experienced differences in both service level and quality of the VTS. They further emphasized that the service has a positive impact on maritime safety, but that they are never sure about what to expect from the VTS operators, e.g. the navigators did not know whether VTS operators have prior experience from working at sea.

Furthermore, it was observed that there are differences in the reporting language. In some countries it is mandatory to report in the national language, e.g. reporting in German in German VTS areas, generally limiting the possibility to receive information on the VHF for all navigating teams that are using a pilot, and do not have sufficient language training in the national language.

Another aspect stressed by the informants is the need for the right information at the right time. The navigators argued that there is already enough information transmitted through the VHF and that the VTS should limit its information to the most important aspects.

Finally, although all officers acknowledged the positive impact of the VTS for the maritime domain, concerns were raised whether the VTS could become something more than solely an information service. It is hard to build up the same "picture" of a situation via the VHF and that makes it difficult to transfer control to the shore-side service as both parts do not only have to understand, but also to trust each other [16].

\section{Discussion}

The results of the studies indicate that risk and safety in the VTS domain are highly context- dependent. Working experience, both on board and on shore, was identified as the key ingredient of good and safe VTS service. Furthermore, both navigators and VTS operators stressed that dynamic risk management should not only focus on new technological inventions. It is important to emphasize the nontechnical decision support at hand, such as procedures, checklists, and guidelines. This non-technical support is a big part of the daily work of operators both on shore and on board. Unfortunately, the informants in the studies often felt that they did not support their work as such, but increased the paper work and the overall workload. Therefore it is important to compose guidelines, checklists and procedures which are meaningful from an operator's perspective so that they are an actual support and not a burden.

All participants in the studies further raised concerns about education and language proficiency in the maritime domain as these are the basics for a functioning VTS providing safety-related information and assistance to the shipping community. If education and certification varies a lot between countries, VTS centers and bridge teams, it becomes hard to build mutual trust in each other's competencies. This will have an impact on how much control vessels are prepared to transfer to shore-based stations and it also affects the way that VTS operators handle the traffic in the area.

Furthermore, and that is especially interesting for future approaches in the light of e-Navigation, the participants emphasized the importance to see the same "picture" to be able to build trust in each other's competences. Even though technical advancements allow changes to the decision support systems, not all changes are desirable. A slight change in the technology can lead to an increased workload as this change may ultimately also modify the ways work is conducted by the operator $[17,18]$.

\subsection{Technical user needs}

The VTS operators and navigators in the studies emphasized that the right information must be presented at the right time. What type of information this is and when it is needed, depends on the context of use, e.g. traffic density, geographical and hydrometeorological conditions. The amount of information presented in the support system should always 
be matched to what is needed for the daily work of an operator. Future support system design should bear in mind that decisions are often made based on pattern recognition which is obtained through work experience. It needs to be acknowledged that different information needs may arise from the degree of expertise of an operator.

Further, many operators expressed concern with regards to the trustworthiness of the information displayed in the system, in particular with regards to AIS-based information. Operators must be able to rely on the information which they base their decisions on. Doubt on the trustworthiness of a data source leads to a time-consuming process of double checking. The validity and integrity of a data source must be guaranteed or it needs to be removed from the system altogether.

Additionally, the experts stated that problems in the interaction between shore and ship arise by having differences in the information displayed on shore and on the bridge. These differences must be compensated for, or otherwise be managed, to facilitate the work of the VTS operators.

\subsection{Organizational needs}

Aspects concerning the overall organization of the maritime sector arose from all three studies. It became clear that there is a general need to define the overall scope and goal for the work of the VTS. If the main goal is defined to be safety, then it should be acknowledged that safety is context-dependent and that VTS operators actively promote safety through their work. The national, e.g. Competent Authorities, and international organizations, e.g. International Maritime Organization (IMO), in the maritime sector should therefore be aware of the importance of creating a safety framework of guidelines which is VTScentered, e.g. a clear statement of which services are included in the VTS. A VTS center should not become an overall service center for all the events happening in a VTS area, e.g. VTS operators should not be forced to take fairway maintenance records, answer to port alarms, organize the berthing of ships etc.

Furthermore, it is essential to increase the degree of standardization of the VTS education. The current guidelines concerning the education of VTS operators are formulated quite openly. There is the need for more standardization to guarantee a high level of education which does not differ from country to country and VTS center to VTS center. To be able to cooperate, the navigators need to be able to estimate the competency of the service providing operator to be able to trust him/her.

In addition, a background as a navigator should be obligatory for all VTS operators to guarantee a high degree of understanding of different situations. Although VTS operators are supposed to be trained Master Mariners there is often a lack of practical knowledge of maneuverability of vessels as well as possible actions which can be taken. This practical knowledge is especially important in the case of navigational assistance as the operator must understand the needs of the bridge team.

Further, it is also required to improve the overall communication skills of the VTS operators. As one of the experts stated it: "Kommunikation är en kunskap" (Communication is a science).

Communication needs to be treated as a process, not as singular event, thus, the communication phrases (Short Maritime Communication Phrases, SMPC) and structures introduced should support such a process. Today these communication phrases are too many and they are not as standardized as in similar domains, e.g. aviation. We suggest there should be fewer and more directed phrases which are thoroughly trained throughout the education of an operator [19].

\section{Conclusion}

This article summarizes three studies conducted within the maritime domain. The data were collected by ethnographically inspired methods. The results of the studies show that there are several technical and organizational user needs which need to be taken into account when new approaches to dynamic risk management are established. Technology should not be the only focus when future solutions for VTS systems are developed. Although most attention is often paid to the technological advancements, there is nontechnical support and skills which are built through expertise and working experience. These skills should be acknowledged and fostered by future system design solutions.

In general, the most pressing issue identified is the structural incoherence of the VTS as a service regulated internationally, but implemented nationally. Without a common education and language proficiency, and without a general service level, it is hard to promote safety as those who use VTS, do not know what type of service can be expected. 


\section{Acknowledgements}

We would like to acknowledge the EfficienSea project, the Region of Västra Götaland and the Fru Mary von Sydow, född Wijk, foundation for financing this research.

Furthermore, we would like to express our gratitude to the experts who participated in our studies. Without them sharing their expertise, we would not have anything to present.

\section{References}

[1] International Association of Marine Aids to Navigation and Lighthouse Authorities (IALA). IALA Vessel Traffic Manual. International Association of Marine Aids to Navigation and Lighthouse Authorities, 2008.

[2] Kharchenko, V. and Vasylyev, V. Decision-Making System for Vessel Traffic Planning and Radar Control. In Proceedings of the European Radar Conference (Amsterdam, 2004).

[3] Nuutinen, M., Savioja, P. and Sonninen, S. Challenges of developing the complex socio-technical system: Realising the present, acknowledging the past, and envisaging the future of vessel traffic services. Applied Ergonomics, 28, 2006), 513-524.

[4] Chauvin, C. and Lardjane, S. Decision making and strategies in an interaction situation: Collision avoidance at sea. Transportation Research Part F: Traffic Psychology and Behaviour, 11, 4 2008), 259-269.

[5] Klein, G. A. A Recognition-Primed Decision (RPD) Model of Rapid Decision Making. Ablex, 1993.

[6] Zsambok, C. E. and Klein, G. Naturalistic Decision Making. Lawrence Erlbaum Associates, 1997.

[7] Weick, K. E. Organization culture as a source of high reliability. California Management Review, 29, 2 1987), 112 127.
[8] Roberts, K. H. Some Characteristics of One Type of High Reliability Organization. Organization Science, 1, 2 1990), 160-176.

[9] IMO Guidelines for Vessel Traffic Services. International Maritime Organization, 1997.

[10] Lützhöft, M., Praetorius, G., Bruno, K. and Brödje, A. Dynamic risk management- user need description. Chalmers University of Technology, Gothenburg, 2009.

[11] International Organization for Standardization ISO 9241-11 Ergonomic requirements for office work with visual display terminals (VDTs) International Organization for Standardization, 1998.

[12] Orasanu, J. and Connolly, T. The Reinvention of Decision Making. Ablex, 1993.

[13] Praetorius, G., Lützhöft, M. and Bruno, K. The context matters: Maritime safety in the Vessel Traffic Service (VTS) Domain. In Proceedings of the ESREL 2010. Reliability, Risk and Safety. Back to the Future (Rhodes, 5th September - 9th September 2010, 2010). Taylor \& Francis Group.

[14] Praetorius, G., Bruno, K. and Lützhöft, M. Enacting Reliability: First Steps To Define Safety in the VTS Domain. In Proceedings of the International Conference on Human Performance at Sea, HPAS 2010 (Glasgow, 2010). University Strathclyde Glasgow.

[15] Praetorius, G. and Lützhöft, M. Safety Is Everywhere-The Constituents of Maritime Safety. In Proceedings of the $\mathrm{Hu}$ man Factors and Ergonomics Society 55th Annual Meeting (Las Vegas, 2011). Human Factors and Ergonomics Society

[16] Lützhöft, M. and Bruno, K. Talk and trust before technology: First steps toward shore-based pilotage. 2009.

[17] Woods, D. D. and Dekker, S. Anticipating the effects of technological change: a new era of dynamics for human factors. Theoretical Issues in Ergonomics Science, 1, 3 2000), 272-282.

[18] Woods, D. D., Johannesen, L. J., Cook, R. I. and Sarter, N. B. Behind Human Error: Cognitive Systems, Computers, and Hindsight. Wright-Patterson Air Force Base, CSERIAC SOAR 94-01. Ohio, USA, 1994.

[19] Bruno, K. and Lützhöft, M. Shore-based pilotage: Pilot or autopilot? Piloting as a control problem. Journal of Navigation, 62, 3 2009). 